\title{
Light-Induced Spin Crossover in Fe(II)-based complexes: the full photocycle unraveled by ultrafast Optical and X-ray Spectroscopies
}

\author{
A. Cannizzo, C. J. Milne, C. Consani, W. Gawelda ${ }^{*}$, Ch. Bressler ${ }^{\dagger}$, F. van Mourik and \\ M. Chergui \\ Ecole Polytechnique Fédérale de Lausanne, Laboratoire de Spectroscopie Ultrarapide (LSU), \\ ISIC, Faculté des Sciences de Base, BSP, CH-1015 Lausanne-Dorigny, Switzerland
}

\begin{abstract}
:
The light-induced ultrafast spin and structure changes upon excitation of the singlet metal-toligand-charge-transfer ( $\left.{ }^{1} \mathrm{MLCT}\right)$ state of Fe(II)-polypyridine complexes are investigated in detail in the case of aqueous iron(II)-tris-bipyridine $\left(\left[\mathrm{Fe}^{\mathrm{II}}(\mathrm{bpy})_{3}\right]^{2+}\right)$ by a combination of ultrafast optical and X-ray spectroscopies. Polychromatic femtosecond fluorescence upconversion, transient absorption studies in the 290-600 $\mathrm{nm}$ region and femtosecond X-ray absorption spectroscopy allow us to retrieve the entire photocycle upon excitation of the ${ }^{1}$ MLCT state from the singlet low spin ground state $\left({ }^{1} \mathrm{GS}\right)$ as the following sequence: ${ }^{1,3} \mathrm{MLCT} \rightarrow{ }^{5} \mathrm{~T} \rightarrow{ }^{1} \mathrm{GS}$, which does not involve intermediate singlet and triplet ligand field states. The population time of the HS state is found to be $\sim 150 \mathrm{fs}$, leaving it in a vibrationally hot state that relaxes in 2-3 ps, before decaying to the ground state in $650 \mathrm{ps}$. We also determine the structure of the high-spin quintet excited state by picosecond X-ray absorption spectroscopy at the $K$ edge of Fe. We argue that given the many common electronic (ordering of electronic states) and structural (Fe-N bond elongation in the high spin state, Fe-N mode frequencies, etc.) similarities between all $\mathrm{Fe}(\mathrm{II})$-polypyridine complexes, the results on the electronic relaxation processes reported in the case of $\left[\mathrm{Fe}^{\mathrm{II}}(\mathrm{bpy})_{3}\right]^{2+}$ are of general validity to the entire family of Fe(II)-polypyridine complexes.
\end{abstract}

KEYWORDS: Spin Crossover, pump-probe spectroscopy, ultrafast, optical absorption, Xray absorption, Fluorescence up-conversion

\footnotetext{
* Now at: Laser Processing Group, Instituto de Óptica, CSIC, Serrano 121, E-28006 Madrid, Spain

${ }^{\dagger}$ Now at : XFEL, DESY, Notkesstrasse 85, D-22603 Hamburg, Germany

*Corresponding author : majed.chergui@epfl.ch
} 


\section{INTRODUCTION:}

The phenomenon of Spin Crossover (SCO), which implies an electron spin flip between a low spin (LS) ground state and a high spin (HS) excited state (or the reverse) in metal-based molecular complexes has been demonstrated for derivatives of ions with $d^{4}, d^{5}, d^{6}$ and $d^{7}$ configurations and is observed for all these in complexes of the first transition series [1].

SCO can be triggered by temperature, pressure or light irradiation and research on the latter witnessed a major development after McGarvey et al [2,3] discovered that for a number of iron(II) and iron(III) polypyridine complexes in solution, the HS state could be populated efficiently at the expense of the LS state by pulsed laser excitation. Near ambient temperatures these light-induced HS states have lifetimes ranging from nanoseconds to microseconds, which are governed by the HS to LS relaxation kinetics. Following this discovery, Decurtins et al [4] showed that at cryogenic temperatures, the HS/LS relaxation slows down such that under continuous irradiation, the iron(II) spin-crossover systems can be trapped in the HS state, for which the expression "light-induced excited state spin trapping (LIESST)" was coined. The discovery of LIESST triggered several years of intense research not only with regard to the mechanism of trapping in the HS state of the system but also to the chemical and physical parameters governing the lifetimes of the low-temperature metastable HS states [513]. The fact that LIESST can be observed in crystalline solids raised the interest for the study of cooperative effects. The interest for spin trapping is not just academic but is also stirred by the potential applications in optical writing/magnetic reading for magnetic data storage [14]. Iron(II) polypyridine complexes are also considered as potential (and cheaper) candidates for dye-sensitized solar cells [15], so far mainly successful with Ruthenium-based complexes. Finally, Fe(II) polypyridine complexes appear to have several photophysical properties in common with metalloporphyrins, which play an important role in photosynthesis, respiration and oxygen transport.

Several studies have been carried out to characterize the spectroscopic, magnetic, structural and dynamical properties of Fe(II) complexes that differ by their ligands, with the aim of identifying the parameters that are crucial to an efficient SCO. In particular, the aim was to identify what controls the lifetime of the lowest excited quintet state, which differs by several orders of magnitude depending on the nature of the ligand, and to identify the route leading from the initially excited state to the lowest quintet state in the LIESST process. These studies are nicely collected in two volumes published in 2004 that were dedicated to SCO complexes [1]. What is striking from these studies is that several electronic and structural properties are common to nearly all Fe(II)-based SCO complexes. This is of importance as properties that 
are determined for one complex could to a certain extent be generalized to the rest of the family of Iron(II)-based complexes. Below we briefly review these properties and concentrate on the photocycle of the smallest member of the family of Iron(II)-based polypyridine complexes, Iron(II)-tris-bipyridine $\left(\left[\mathrm{Fe}^{\mathrm{II}}(\mathrm{bpy})_{3}\right]^{2+}\right)$, for which the SCO process can only be triggered by light. We will present our recent results using a combination of ultrafast optical transient absorption, ultrafast fluorescence up-conversion and picosecond and femtosecond transient X-ray absorption spectroscopy that allows us to unravel the full details of the structural dynamics and relaxation pathways of the photoinduced LS to HS conversion. We feel this study is paradigmatic to the entire family of light-induced SCO processes.

\section{I. PROPERTIES OF Fe(II) COMPLEXES}

\subsection{Electronic structure:}

Iron(II) consists of 6 electrons in the $3 \mathrm{~d}$ shell. In perfectly octahedral $\mathrm{O}_{\mathrm{h}}$ coordination, the five nd orbitals of a transition metal ion are split into a subset of three orbitals, namely $\mathrm{d}_{\mathrm{xy}}, \mathrm{d}_{\mathrm{yz}}$ and $\mathrm{d}_{\mathrm{zx}}$, which are basis to the irreducible representation $\mathrm{t}_{2 \mathrm{~g}}$, and a subset of two orbitals, namely $\mathrm{d}_{\mathrm{z}}{ }^{2}$ and $\mathrm{d}_{\mathrm{x}-\mathrm{y}}^{2}{ }^{2}$, which are basis to the irreducible representation $\mathrm{e}_{\mathrm{g}}$ (see Figure 1a). The $\mathrm{t}_{2 \mathrm{~g}}$ orbitals are basically non-bonding and are therefore at lower energy than the anti-bonding $\mathrm{e}_{\mathrm{g}}$ orbitals. The splitting between the two sets is referred to as ligand field splitting and is symbolized by the parameter of the ligand field strength. The latter depends upon both the particular set of ligands and the given metal ion. Because the spin cross-over consists in transferring electrons from the $\mathrm{t}_{2 \mathrm{~g}}$ subshell to the $\mathrm{e}_{\mathrm{g}}$ subshell, the Fe-N bond length increases. Figure 1 shows a typical potential energy level diagram along the $\mathrm{Fe}-\mathrm{N}$ coordinate. The essential electronic states are shown: the ${ }^{1} \mathrm{~A}_{1}\left(\mathrm{t}_{2 \mathrm{~g}}{ }^{6}\right)$ low-spin ground state, the lowest excited ${ }^{5} \mathrm{~T}_{2}\left(\mathrm{t}_{2 \mathrm{~g}}{ }^{4} \mathrm{e}_{\mathrm{g}}{ }^{2}\right)$ high-spin electronic state, as well as the higher excited singlet, triplet and quintet ligand-field (LF, also called metal-centred) states. In addition, the manifold of low-lying singlet and triplet metal-ligand charge transfer (MLCT) states for ligands with extended $\pi$ systems is shown as a shaded region. This diagram is rather general to the family of Fe(II)based molecular complexes, in terms of the ordering of states but not in their absolute energies, as can be gathered from the absorption spectra of the various complexes [12], and from quantum-chemical calculations on complexes such as $\left[\mathrm{Fe}^{\mathrm{II}}(\mathrm{bpy})_{3}\right]^{2+}[16],\left[\mathrm{Fe}^{\mathrm{II}}(\mathrm{ptz})_{6}\right]^{2+}$ (ptz=1-propyltetrazole) [17], and [Fe $\left.{ }^{\mathrm{II}}(\mathrm{tz})_{6}\right]^{2+}(\mathrm{tz}=1-\mathrm{H}$-tetrazole) [18].

\subsection{Molecular structure}


Per electron that is promoted from the $t_{2 g}$ to the $e_{g}$ orbital, the metal-ligand bond length increases by as much as $0.1 \AA$ [19]. In the low-spin ${ }^{1} \mathrm{~A}_{1}\left(\mathrm{t}_{2 \mathrm{~g}}{ }^{6}\right)$ state, the bond length is centred around $1.96 \AA$ with a spread of $\pm 0.04 \AA$, in the high-spin ${ }^{5} \mathrm{~T}_{2}\left(\mathrm{t}_{2 \mathrm{~g}}{ }^{4} \mathrm{e}_{\mathrm{g}}{ }^{2}\right)$ state, the bond length increases by $0.20 \AA$ typically $[18,20]$. Obviously these parameters change somewhat with the type of ligand. They have been determined by static X-ray diffraction and X-ray absorption spectroscopy studies of complexes on the LS state and on the metastable quintet states [2123]. For the series of states ${ }^{1,3} \mathrm{~T}_{1,2}\left(\mathrm{t}_{2 \mathrm{~g}}{ }^{5} \mathrm{e}_{\mathrm{g}}{ }^{1}\right)$, the bond length is expected to be intermediate between the LS and HS state, and for the ${ }^{5} \mathrm{E}\left(\mathrm{t}_{2 \mathrm{~g}}{ }^{3} \mathrm{eg}_{\mathrm{g}}{ }^{3}\right)$ state it is expected to be larger than the one of the ${ }^{5} \mathrm{~T}_{2}$ state. This is confirmed by quantum-chemical calculations [18, 20, 24]. In the case of the ${ }^{1,3} \mathrm{~T}$ states, the similar bond distances are also to a certain extent corroborated by the width of the absorption bands from the ground state to these states, that are observed at low temperatures [12].

\subsection{Vibrational modes:}

Another property that is common to all $\mathrm{Fe}(\mathrm{II})$-based complexes is their $\mathrm{Fe}-\mathrm{N}$ bond stretch frequency, which lies around $390-430 \mathrm{~cm}^{-1}$ in the LS state and around $210-250 \mathrm{~cm}^{-1}$ in the HS state [25], supporting the idea of a softer potential due to more antibonding character in the HS state.

\subsection{Ultrafast relaxation kinetics}

The kinetics of light-induced SCO has been characterized by conventional and ultrafast laser techniques over the past few years [12, 26-32]. The studies by Hendrickson, McCusker and co-workers were carried out on over 10 different $\mathrm{Fe}(\mathrm{II})$ polypyridine complexes (including $\left.\left[\mathrm{Fe}^{\mathrm{II}}(\mathrm{bpy})_{3}\right]^{2+}\right)$, and indirectly inferred that the relaxation from the initially excited ${ }^{1} \mathrm{MLCT}$ state to the lowest ${ }^{5} \mathrm{~T}_{2}$ quintet state occurs in $\leq 1$ ps. This stresses again the underlying common behaviour of these systems in spite of their different ligands. Subsequently, the quintet state relaxes non-radiatively to the LS ground state with times ranging from $\sim 0.65 \mathrm{~ns}$ to $\sim 150 \mathrm{~ns}$ in aqueous solution at room temperature [33]. This was established by correlating the time scale of the ground state bleach recovery, with the decay time of the quintet excited state absorption, which was found to lie in the $300 \mathrm{~nm}$ region [12, 28, 34]. However, the details of the intermediate steps going from the initially accessed ${ }^{1}$ MLCT state to the ${ }^{5} \mathrm{~T}_{2}$ state have not been resolved, due to the lack of spectroscopic observables of the intermediate ${ }^{1,3} \mathrm{~T}$ ligand field states (Figure 1), and it was suggested that the population of the ${ }^{5} \mathrm{~T}_{2}$ state is fed from the ${ }^{1}$ MLCT excitation via the manifold of the LF states [12, 31, 32]. 


\section{EXPERIMENTAL STRATEGIES}

Very diverse experimental strategies have been implemented to determine the structure and dynamics of Fe(II) SCO complexes having short HS lifetimes. Since we concentrate on our studies, we will here briefly recall the experimental methodologies we implemented.

$i$. Femtosecond resolved fluorescence: the measurements were performed using an upconversion set up with broadband detection, which allows us to record entire spectra as a function of time delay after excitation [35-38]. We performed fluorescence measurements in the 440-690 nm detection range, with a temporal resolution of $~ 100 \mathrm{fs}$, upon excitation with $400 \mathrm{~nm}, 40 \mathrm{fs}$ pulses. The fluorescence signal, collected in a forward scattering geometry, was up-frequency converted in a $250 \mu \mathrm{m}$ thick BBO crystal by mixing with a pulse at $800 \mathrm{~nm}$ (the so called gate pulse). The up-converted signal is spatially filtered and detected in polychromatic mode with a spectrograph and a liquid- $\mathrm{N}_{2}$ cooled CCD camera.

ii. Transient Absorption in the UV-Vis: the measurements used 150 fs pulses at $400 \mathrm{~nm}$ for excitation. Probing is done using a broadband white light continuum covering the $370-650 \mathrm{~nm}$ and the 290-370 $\mathrm{nm}$ ranges, which is dispersed after the sample in a spectrometer and detected by a diode array, allowing single-shot detection of transmission. The probe beam was detected at the nominal repetition rate of the laser $(1 \mathrm{kHz})$, so that the adjacent pairs of pumped and unpumped spectra are obtained delivering, after subtraction, the transient spectra. More details about this set-up are given in ref. [39].

iii. Picosecond transient hard X-ray absorption spectroscopy: in order to determine the structure of the short lived HS state, we used picosecond X-ray absorption spectroscopy, described in refs [40-42]. X-ray absorption spectra are characterized by absorption edges, which are atom specific and are due to excitation of core electrons to the ionization threshold. They contain fine structure in the low energy part (the so-called X-ray absorption near-edge structure or XANES), and in the high energy region, tens to several hundreds of eVs above the edge (the so-called extended X-ray absorption fine structure or EXAFS). The XANES features just below the Fermi level are due to bound-bound transitions from the atom core orbital to the valence orbitals, and they thus deliver information about the electronic structure (oxidation state, occupancy of valence orbitals, charge transfer, etc.). XANES also contains above-ionization multiple scattering resonances, whose analysis can deliver information about 
bond distances and angles, and coordination numbers. Well above the edge (typically $>50$ $\mathrm{eV})$ lies the EXAFS region, which is dominated by single scattering events, and gives information about bond distances and coordination numbers of the nearest neighbours around the absorbing atom. The laser-pump/x-ray-probe experiments were performed at the microXAS beamline of the Swiss Light Source (SLS). The methodology of transient X-ray absorption spectroscopy (XAS) has been described in detail in refs [40, 41, 43, 44]. Pumping the system is achieved by $115 \mathrm{fs}, 400 \mathrm{~nm}$ laser pulses, while probing is done by monochromatic and tunable hard x-ray pulse of 70 ps temporal width, which is spatially and temporally overlapped with the laser pump pulse onto the sample. The photoinduced changes at the K-edge of the Iron atom (near $7.2 \mathrm{keV}$ ) are monitored during the experiment as a function of the adjustable pump-probe time delay $\Delta \mathrm{t}$. The detected signal is the difference $\mathrm{X}$ ray absorption spectrum (recorded in both $\mathrm{x}$-ray transmission and fluorescence modes) between the laser excited and the unexcited sample, recorded on a shot-to-shot basis at $2 \mathrm{kHz}$, twice the repetition rate of the laser pump pulse. In all experiments, the sample is a freeflowing liquid jet of an aqueous solution of 1-100 $\mathrm{mM}$ of the complex.

\section{$i v$. Femtosecond transient hard X-ray absorption spectroscopy}

In order to follow the ultrafast LS to HS change, we used femtosecond XAS at the K-edge of Iron following excitation of the system. Femtosecond hard X-ray pulses were extracted from the synchrotron using the so-called slicing scheme $[45,46]$. The trade-off of this technique is that the X-ray photon flux decreases by three orders of magnitude, making the data acquisition times significantly longer than with picosecond pulses. Two important upgrades made these measurements possible: 1) installation of Ge(111) X-ray monochromator crystals which provide double the bandwidth of $\mathrm{Si}(111)$, reducing the energy resolution but increasing the $\mathrm{X}$ ray flux, and 2) increasing the slicing laser repetition rate from $1 \mathrm{kHz}$ to $2 \mathrm{kHz}$, essentially halving the data acquisition times.

\section{RESULTS AND DISCUSSION}

\subsection{Femtosecond Fluorescence Spectroscopy}

Figure 2a shows a typical 2D fluorescence spectrum obtained upon excitation of aqueous $\left[\mathrm{Fe}^{\mathrm{II}}(\mathrm{bpy})_{3}\right]^{2+}$ at $400 \mathrm{~nm}$ [47]. The time-dependent emission spectra, which are shown in Figure $2 b$, are obtained by taking slices at fixed time delay, while cuts at fixed emission wavelength provide the kinetic traces, shown in Figure 2c. Strikingly, the emission shows up in the 500-650 $\mathrm{nm}$ region already at $\mathrm{t}=0$ and is very short lived, i.e. on the order of the 
instrument temporal response ( $110 \mathrm{fs})$. In addition, in Fig. 2a a weak emission shows up at $\lambda$ $\geq 650 \mathrm{~nm}$ and $\mathrm{t} \geq 100$ fs. This observation is confirmed in Fig. $2 \mathrm{~b}$, where the spectrum at $\mathrm{t}=$ $100 \mathrm{fs}$ exhibits two weak bands of almost identical intensity, one centered at $\sim 600 \mathrm{~nm}$, the other at $\sim 660 \mathrm{~nm}$. The former is the remnant of the main emission at earlier times. We also verified that no other emissions occur at longer times, by recording scans up to 250 ps time delay. The comparison of Raman and emission time traces (Fig. 2c) suggests a rise and a decay of the fluorescence almost within the cross-correlation of our experiment ( 110 fs) for all kinetic traces at $<650 \mathrm{~nm}$. These results bear strong analogy with previous ones on $\left[\mathrm{Ru}^{\mathrm{II}}(\mathrm{bpy})_{3}\right]^{2+}[37]$. Indeed, likewise the kinetic traces at $<650 \mathrm{~nm}$ in Fig. $2 \mathrm{c}$ are best fitted with an exponential decay of $30 \pm 10$ fs convoluted with the instrumental response. The main emission at $\sim 600 \mathrm{~nm}$ is due to ${ }^{1}$ MLCT fluorescence, while the weak band at $\sim 660 \mathrm{~nm}$ is assigned to the ${ }^{3} \mathrm{MLCT}$ state. The latter assignment is based on the fact that, just as in $\left[\mathrm{Ru}^{\mathrm{II}}(\mathrm{bpy})_{3}\right]^{2+}$, the ${ }^{1} \mathrm{MLCT}$ decays to the ${ }^{3}$ MLCT on similar very short timescales. This is the first observation of fluorescence and phosphorescence for Fe(II)-SCO complexes. However, their quantum yields are extremely weak. Typically, taking for the purely radiative lifetimes of the ${ }^{1}$ MLCT and ${ }^{3}$ MLCT states $10 \mathrm{~ns}$ and $10 \mu$ s, respectively, and the measured lifetimes of $<30$ fs and $\sim 130 \mathrm{fs}$, we estimate the quantum yield to be $10^{-6}$ and $10^{-8}$ for the fluorescence and phosphorescence, respectively! Thus Fe(II)-complexes can by no means be considered luminescent materials, as is the case with $\left[\mathrm{Ru}^{\mathrm{II}}(\mathrm{bpy})_{3}\right]^{2+}$ due to its long-lived phosphorescence.

\subsection{Femtosecond visible transient absorption spectroscopy:}

In order to further analyse the decay of the triplet state, we performed transient absorption measurements. Figure 3 a shows representative spectra recorded at various time delays within the initial 2 ps after photoexcitation. A short-lived excited state absorption (positive signal) appears in the $340-440 \mathrm{~nm}$ region while in the $560-640 \mathrm{~nm}$ range, it is present even at longer time delays. This excited state absorption is a signature of the MLCT state, since it corresponds to the absorption of the reduced bpy ligand, as already established from spectroelectrochemical studies of Fe(II)p-polypyridine complexes [48], and in the case of $\left[\mathrm{Ru}^{\mathrm{II}}(\mathrm{bpy})_{3}\right]^{2+}$ for which the ${ }^{3} \mathrm{MLCT}$ state is long-lived [49]. In $<200 \mathrm{fs}$, the short wavelength $(<400 \mathrm{~nm})$ excited state absorption is replaced by a negative signal, which we identify as the ground state bleach (GSB) signal, caused by depletion of the ground state due to the photoexcitation by the pump pulse. This bleach signal is dominant in the $450-550 \mathrm{~nm}$ spectral range and it fully reflects the ground state absorption. Kinetic traces at three characteristic wavelengths $(370 \mathrm{~nm}, 523 \mathrm{~nm}$ and $630 \mathrm{~nm})$ are shown in Fig. 3b. It can be seen 
that the positive absorption signals at 370 and $630 \mathrm{~nm}$ appear within the experimental temporal resolution of $140 \mathrm{fs}$, but behave differently, as already noted in Fig. 3a. The $630 \mathrm{~nm}$ trace is due to the strong absorption of aqueous electrons, which are produced in small quantities by multiphoton excitation, as established from pump power dependence studies [50].

Our analysis and model [47] globally delivered three time constants: $115 \pm 10 \mathrm{fs}$, $960 \pm 100 \mathrm{fs}$ and $665 \pm 35$ ps that fitted simultaneously all the kinetic traces in the spectral range of interest. The shortest component reflects the lifetime of the ${ }^{3}$ MLCT state, in agreement with the fluorescence up-conversion measurements ( $\S$ III.a), while the longest component reflects the ground state recovery time and is associated with the decay of the ${ }^{5} \mathrm{~T}_{2}$ state and the population of the ${ }^{1} \mathrm{~A}_{1}$ ground state. The intermediate component could not be associated to any given photoinduced species in a straightforward way, and is most probably due to the solvated electron. Finally, information about a channel via the intermediate ${ }^{1,3} \mathrm{~T}$ states could not be retrieved from these data as these states seem specroscopically silent in the region of our probe wavelength range. We will see that femtosecond XAS allow us to nail down the pathways of the LS-to-HS cascade.

\subsection{Structure of the high spin state:}

As already mentioned above, for Fe(II) complexes with long-lived metastable HS states, quasi-static X-ray diffraction and X-ray absorption spectroscopy studies determined the Fe-N bond elongation to be $\sim 0.2 \AA$ with respect to the ground state, independent of the ligands [21]. For short lived HS states with ns and sub-ns lifetimes, one may ask if the bond elongation is also similar. Quantum-chemical calculations indeed predicted this to be the case for $\left[\mathrm{Fe}^{\mathrm{II}}(\mathrm{bpy})_{3}\right]^{2+}[24]$, but in order to confirm it, only time-resolved X-ray techniques with picosecond resolution are capable of delivering the structure. Using the above described strategy for picosecond transient XAS [43], Khalil et al [51] determined the structure of $\left[\mathrm{Fe}^{\mathrm{II}}\left(\operatorname{tren}(\mathrm{py})_{3}\right)\right]^{2+} \quad(\operatorname{tren}(\mathrm{py})=\operatorname{tris}(2$-pyrdilmethyliminoethyl $))$ in acetonitrile solution, whose HS lifetime is $60 \mathrm{~ns}$ and found an elongation of $0.21 \pm 0.03 \AA$. In the case of $\left[\mathrm{Fe}^{\mathrm{II}}(\mathrm{bpy})_{3}\right]^{2+}$, the HS lifetime is $650 \mathrm{ps}$ and with the $70 \mathrm{ps}$ time resolution of the Swiss Light Source synchrotron, the transient HS structure can be captured, especially considering that the unit quantum efficiency for population of the ${ }^{5} \mathrm{~T}_{2}$ state and its rise time of $<1$ ps imply a bottleneck to population relaxation.

Fig. 4a shows the static K-edge XAS spectrum of a $25 \mathrm{mM}$ aqueous $\left[\mathrm{Fe}^{\mathrm{II}}(\mathrm{bpy})_{3}\right]^{2+}$ complex. It is characterized by a number of XANES features, which are 
displayed in the inset and have already been discussed for similar ferrous molecular complexes $[52,53]$. Suffices it to say that all have been shown to undergo significant changes upon light-, pressure- or temperature-induced spin transitions in steady state XAS studies [22, 23, 52-55]. Important to note is that the B-band is a multiple scattering (i.e. a structural) feature, as was clearly shown in ref. [53]. Most of these changes have been attributed to changes of metal-ligand and intraligand bond distances and angles, with the Fe-N bond being the dominant contributor. Additional changes in the high energy (EXAFS) region were also clearly observed, which likewise point to a significant Fe-N bond change [22, 23, 55-57].

Figure $4 \mathrm{~b}$ shows the transient difference spectrum measured 50 ps after laser excitation. All the above mentioned changes are indeed occurring as a result of laser excitation and transient population of the ${ }^{5} \mathrm{~T}_{2}$ state. That the latter is responsible for these changes is confirmed by the inset showing the temporal evolution of the absorption changes at the B-feature $(7126 \mathrm{eV})$ which maps the lifetime of the quintet state measured by optical laser spectroscopy [58]. The structural analysis of the excited state based on the transient XANES and EXAFS spectra was carried out in two ways: i) fitting an excited state EXAFS spectrum that was generated from the transient spectrum, and the prior knowledge of the photolysis yield [58], as shown in figure 5a; ii) fitting directly the transient spectrum in energy space as described in ref. [59] and shown in figure 5b. These deliver the same Fe-N bond elongation $\Delta R_{\mathrm{Fe}-\mathrm{N}}=0.20 \AA$, but the precision is increased considerably using the latter procedure $(0.203 \pm$ $0.008 \AA$ A). Thus, along with the results of Khalil et al. for a complex with 60 ns HS lifetime [51], and of those of the literature for metastable HS states [21], our result on the shortest lived HS complex shows that the Fe-N bond elongation in the HS state is nearly the same for all $\mathrm{Fe}(\mathrm{II})$-polypypridine complexes. It is thus not the parameter that controls the quintet state lifetime. Rather, the adiabatic energy and the coupling parameters between low spin and high spin state are the crucial parameters. Indeed, of all Fe(II)-SCO complexes, $\left[\mathrm{Fe}^{\mathrm{II}}(\mathrm{bpy})_{3}\right]^{2+}$ has the highest lying quintet state.

\subsection{The LS to HS pathway: a femtosecond XANES study}

As discussed in $\S \S$ III.a and III.b, our optical studies identified that the population relaxation from the ${ }^{3}$ MLCT state occurs in $\sim 130$ fs. The cascade down to the HS state could not be followed due to the fact that no spectroscopic observables are known of the intermediate ${ }^{1,3} \mathrm{~T}$ states. In order to circumvent this limitation, we carried out a femtosecond XANES study of $\left[\mathrm{Fe}^{\mathrm{II}}(\mathrm{bpy})_{3}\right]^{2+}$ exploiting the fact that the multiple-scattering B-feature is sensitive to the $\mathrm{Fe}-\mathrm{N}$ bond elongation. Indeed, Figure $4 \mathrm{~b}$ shows that in the quintet state its 
intensity increases causing the significant peak at low energy in the transient spectrum. This sensitivity to the Fe-N bond length is supported by simulations based on multiple scattering theories [42]. Thus because the ${ }^{1,3} \mathrm{~T}$ state all lie at an intermediate distance between the LS and HS states (Figure 1), in principle one should be able to identify the various electronic states possibly involved in the relaxation cascade, by the amplitude of the B-feature.

Using hard X-ray fs pulses generated by the slicing scheme at the Swiss Light Source [46], we carried out an optical pump/X-ray probe experiment following the evolution of the B-feature as a function of pump-probe delay. Figure 6 presents the time scan obtained at the B-feature $(7.122 \mathrm{keV})$ showing that the signal stabilizes from about $300 \mathrm{fs}$ up to the scan limit of $10 \mathrm{ps}$ (see inset), which is evidence that the system is already in the HS state. Further evidence is the energy scan at $300 \mathrm{fs}$, which reproduces the transient spectrum at $50 \mathrm{ps}$ time resolution (Figure 7b). The fit in figure 6 shows that the quintet state is reached in $150 \pm 50 \mathrm{fs}$. This time corresponds to the decay of the ${ }^{3}$ MLCT state, determined in the optical studies (see $\S \S 4.1$ and 4.2) implying that the ultrafast spin conversion is a simple three-step ${ }^{1}$ MLCT ${ }^{3} \mathrm{MLCT}-{ }^{5} \mathrm{~T}_{2}$ cascade that bypasses the intermediate ${ }^{1,3} \mathrm{~T}$ states.

This cascade resolves a number of issues that were being discussed in the literature: i) the exclusion of the ${ }^{1,3} \mathrm{~T}$ states solves the problem of multiple ultrafast intersystem crossing steps, which have to occur on an ultrafast time scale between states that are quasi-parallel with respect to the Fe-N coordinate (i.e. with poor vibrational overlap, Figure 1); ii) the unit quantum efficiency of the SCO process from the ${ }^{1}$ MLCT state into the quintet state makes now sense in the context of excluding any leakage back to the ground state through the bypassing of the ${ }^{1,3} \mathrm{~T}$ states. It is also interesting to note that the ${ }^{1} \mathrm{~A}_{1} \rightarrow{ }^{1} \mathrm{MLCT} \rightarrow{ }^{3} \mathrm{MLCT} \rightarrow{ }^{5} \mathrm{~T}_{2}$ mechanism we unravel is quite close to the mechanism proposed by Hendrickson and coworkers in 1993, except that they did not include the ${ }^{3}$ MLCT state in their cascade [27]. However, given the time scale of the ${ }^{1}$ MLCT $\rightarrow{ }^{3}$ MLCT ISC [47], the presence of a weak ${ }^{3}$ MLCT absorption on the red edge of the ${ }^{1}$ MLCT absorption, and the fact that the latter has an absorption coefficient that is one order of magnitude smaller that of organic dyes with pure singlet states, suggests that the singlet and triplet MLCT states are strongly mixed. Surprisingly, the initially proposed relaxation mechanism was later replaced by a mechanism invoking the intermediate ${ }^{1,3} \mathrm{~T}$ state that would be strongly mixed. This statement does not seem to be supported by the low temperature steady-state spectroscopic studies [12], which point to a clear classification of the LF states according to their spin quantum number.

The proposed mechanism could also have been derived from the steady-state spectroscopic studies at cryogenic temperatures, which showed that excitation into the ${ }^{1,3} \mathrm{~T}$ states leads to 
population of the ${ }^{5} \mathrm{~T}_{2}$ state with a quantum efficiency of $\sim 80 \%$ [12]. However, for excitation of the ${ }^{1}$ MLCT state, the relaxation process was reported to occur with $100 \%$ efficiency at both $10 \mathrm{~K}[60]$ and at room temperatures [61, 62]. This high efficiency would suggest a direct decay of the ${ }^{1}$ MLCT state to the HS state, since including the intermediate ${ }^{1,3}$ T states can only decrease the conversion efficiency. However, this conclusion was not reached, and the authors opted for the sequential relaxation cascade via the ${ }^{1,3} \mathrm{~T}$ states.

Finally, it is important to stress that our conclusions about the SCO mechanism we unravel apply to excitation of the ${ }^{1}$ MLCT state. LIESST via the ${ }^{1,3}$ LF state [12] surely follows different relaxation pathways on different time scales, which still need to be unravelled. The time scale of $\sim 150$ fs corresponds to about two oscillations of the Fe-N stretch vibration [25], suggesting a near non-Born-Oppenheimer process. This experiment illustrates the power of ultrafast XAS to retrieve dynamical information difficult to obtain by laser-only experiments. It also shows how structural dynamics studies can identify the electronic relaxation pathways of complex molecules, while so far the opposite was common practice.

\subsection{Vibrational cooling in the HS state}

A direct ${ }^{3}$ MLCT to ${ }^{5} \mathrm{~T}_{2}$ transition implies that $\sim 1.3 \mathrm{eV}[24,47]$, corresponding to the energy difference of the relative minima, is stored as vibrational energy in the HS state. The issue of vibrational energy storage and relaxation in the quintet state of $\mathrm{Fe}(\mathrm{II})$-polypyridine complexes is important and has mainly been studied by time-resolved resonance Raman spectroscopy [31, 33]. It was also inferred from transient absorption studies to occur in $8 \pm 3$ ps in $\left[\mathrm{Fe}^{\mathrm{II}}\left(\operatorname{tren}(\mathrm{py})_{3}\right)\right]^{2+}[15]$. Recently McCusker, Mathies and co-workers used fs stimulated Raman scattering to study the vibrational relaxation in the HS state of $\left[\mathrm{Fe}^{\mathrm{II}}\left(\operatorname{tren}(\mathrm{py})_{3}\right)\right]^{2+}$ in acetonitrile [34], and reported a bimodal time evolution of the high frequency C-N stretch mode with time constants of $190 \pm 50$ fs and $10 \pm 3$ ps. The latter was attributed to vibrational cooling, while the former was associated with the structural change from LS to HS. Wolf et al [63] reported on a sub-ps IR study of $\left[\mathrm{Fe}^{\mathrm{II}}(\mathrm{btpa})\right]^{2+}$ and $\left[\mathrm{Fe}^{\mathrm{II}}(\mathrm{b}(\mathrm{bdpa})]^{2+}\right.$ in the $1000-1100 \mathrm{~cm}^{-1}$ region, and found relaxation times up to $13 \mathrm{ps}$. It seems that contrary to the case of the electronic relaxation, the vibrational relaxation in the HS state may be different from complex to complex, which is logical since the vibrational modes change. Nevertheless, the dissipation of excess vibrational energy is still not fully understood, but there should be some general trends that one may extract from the study of the different complexes. In this respect, a symmetric complex such as $\left[\mathrm{Fe}^{\mathrm{II}}(\mathrm{bpy})_{3}\right]^{2+}$ offers a simple case to start disentangling the various regimes of vibrational relaxation. Given that the main reaction coordinate for the spin 
change is the Fe-N bond elongation, which is of relatively low frequency $\left(220 \mathrm{~cm}^{-1}\right)$ [25], ultrafast infrared or Raman experiments are difficult to implement. Rather, we exploit the fact that the HS state of Fe(II)-complexes absorbs in the $300 \mathrm{~nm}$ region [12, 27, 29, 34], and use visible pump/UV continuum (290-370 nm) probe spectroscopy with a resolution of $\sim 130 \mathrm{fs}$ ( $\S$ II.2) to directly follow the vibrational relaxation in the HS of aqueous $\left[\mathrm{Fe}^{\mathrm{II}}(\mathrm{bpy})_{3}\right]^{2+}$.

Figure 8 shows a representative selection of UV TA spectra for different time delays. The positive region between $300 \mathrm{~nm}$ and $\sim 330 \mathrm{~nm}$ corresponds to an excited state absorption (ESA), while elsewhere in the spectrum, a bleach signal is dominant, which matches quite well the ground state absorption spectrum above $350 \mathrm{~nm}$ (see figure 3). The ESA is due to the quintet state, as evidenced by its decay time of 650-700 ps (see bottom inset, Figure 8), but the kinetics also exhibits a short component of 2-3 ps. By normalizing the absorption spectrum to the TA spectrum above $350 \mathrm{~nm}$, which consists of only the ground state bleach (GSB) signal, we could retrieve the absorption spectrum of the quintet state at different time delays (top inset, figure 8). The long-time spectra agree with those of stable and metastable HS Fe(II)complexes [12, 27, 29, 34].

Kinetic traces between 300 to $360 \mathrm{~nm}$ are shown in figure 9. The traces in the ESA region are all characterized by a fast rise followed by an oscillatory pattern and a longer decaying component. The oscillations at the blue and red edges of the ESA (300 and $325 \mathrm{~nm}$ ) exhibit a phase shift close to $\pi$ (vertical lines, Figure 9), which is typical of a wave packet oscillating between the turning points of the potential surface on which it evolves. These traces were analysed in detail in ref. [64], and we just recall the approach used to fit them. We described the experimental data in terms of an MLCT ESA and ground state bleach (GSB) contributions instantaneously excited and decaying with $130 \mathrm{fs}$ and $650 \mathrm{ps}$, respectively, while the quintet state ESA rises in 130 fs. A bimodal dynamics with $1.1 \pm 0.17$ ps and $3.4 \pm 1.2$ ps time-constants was necessary to obtain the best fit at short times, along with an oscillatory pattern having a period of $254 \pm 2 \mathrm{fs}$, independent of probe wavelength. However, its damping constants varied between $\sim 400$ to $\sim 800$ fs. The fit results show good agreement with the experimental traces over the whole spectral range (Figure 9). The 1.1 and 3.4 ps components describe a narrowing of the quintet state absorption band due to cooling, as actually evidenced by increase of its maximum and the presence of an isobestic point around $305 \mathrm{~nm}$ (figure 8 , top inset).

Vibrational coherences occur on the HS surface because they only appear in the region of the ESA region, and they are absent from the GSB traces above $325 \mathrm{~nm}$ and in the visible region [47]. As the reaction coordinate of the photoexcited LS-HS spin change is the Fe-N 
bond stretching [42]. whose vibrational frequency is $\sim 220 \mathrm{~cm}^{-1}$ ( $\left.\sim 150 \mathrm{fs}\right)$ in the HS state, the observed wave packet is not directly excited by the laser pump pulse, but by the ultrafast elongation of the $\mathrm{Fe}-\mathrm{N}$ bonds, which excites bending modes due an impulsive change of $\mathrm{N}$ Fe-N angle from LS to HS. Based on DFT calculations [65] we attribute the observed oscillation to a combination of chelate ring modes, benzene cycle bending modes and N-Fe-N bending modes. The indirect excitation of wave packets of low frequency modes via laser excited (not necessarily in the form of wave packets) higher frequency ones is rather common in many systems, including metalloporphyrins [66] and organic molecules [67]. The invariance of the oscillation period with probe wavelength suggests that the wave packet is created in a harmonic part of the surface on which it evolves, i.e. near its minimum given the phase shift between the blue most and red most probe wavelengths.

The damping times of the wave packet represent a lower limit of its dephasing time since, as mentioned above they also depend on the probe window. The dephasing causes the coherent (oscillatory) wavepacket dynamics to turn into an incoherent kinetic regime (exponential). Given that the largest dephasing time we found is $\sim 800 \mathrm{fs}$, we associate the 1.1 ps decay component to the dephasing of the $130 \mathrm{~cm}^{-1}$ mode. Concerning the $3.4 \mathrm{ps}$ decay, we associate it to the relaxation time of the (incoherently) excited Fe-N stretch mode in the quintet state. Since the ${ }^{1,3}$ MLCT emission is vibrationally cold already at very early times (< $100 \mathrm{fs})$ ( $\S$ III.a and III.b), at least as far as the high frequency Franck-Condon modes are concerned, upon crossing into the quintet state only the Fe-N stretch and the N-Fe-N chelate modes are excited, which are responsible for the bimodal relaxation regime.

This is the first evidence of the appearance of vibrational wave packets in the HS state of an Fe(II)-complex and a nice example of the ability of vibrational coherent spectroscopy to map out the modes involved in the ultrafast spin changes, potentially in a large class of metalbased molecular complexes.

\section{CONCLUSIONS}

Based on our studies using a combination of ultrafast spectroscopic and structural tools: transient absorption in the visible [47] and in the UV[64] ranges, femtosecond fluorescence up-conversion [47] with broad band detection, and picosecond [58, 59] and femtosecond [42] transient X-ray absorption spectroscopy, we have fully characterised the photocycle of ultrafast spin change of $\left[\mathrm{Fe}^{\mathrm{II}}(\mathrm{bpy})_{3}\right]^{2+}$ in aqueous solutions, shown in figure 11 . The first event is an ultrafast intersystem crossing (ISC) from the ${ }^{1}$ MLCT to the ${ }^{3}$ MLCT state, followed by a second ISC into the quintet state, leaving the latter with a significant excess of vibrational 
energy. The latter relaxes in a bimodal fashion, which we believe to be due to the relaxation of the Fe-N elongation mode and of bending and chelate modes. These are excited coherently and gives rise to wave packet oscillations. Finally, the return to the ground state occurs on a much slower time scale of 650 ps. Given the common electronic, structural and ultrafast kinetic properties of $\mathrm{Fe}(\mathrm{II})$ complexes, we believe that the ultrafast spin relaxation in $\left[\mathrm{Fe}^{\mathrm{II}}(\mathrm{bpy})_{3}\right]^{2+}$ is representative of the entire family of such complexes. However, the vibrational relaxation kinetics differs from complex to complex, just as the well studied HS to LS relaxation back to the ground state. The latter has recently been discussed from a theoretical point of view in the case of Iron carbonyl complexes [68].

The here reported ultrafast spin dynamics may well be generalised to other metal-based molecular complexes, as ultrafast spin changes as large as $\Delta S=2$ have been reported in metalloporphyrins [69] and in mono- and homodi-nuclear $\left[\mathrm{Fe}-\mathrm{M}(\mathrm{PMK})_{3}\right]^{2+}$ and heterodinuclear six-coordinate complexes of general formula $\left[\mathrm{Fe}-\mathrm{M}(\mathrm{PMK})_{3}\right]^{2+}(\mathrm{M}=\mathrm{Fe}, \mathrm{Zn})$ containing iron(II)-iron(II) and iron(II)-zinc(II) couples, with PMK being the bis-bidentate ligand 2-pyridyl-methyl-ketazine [70].

\section{ACKNOWLEDGEMENTS}

This work was funded by the Swiss National Science Foundation (FNRS), via contracts 110464, 107956, 620-066145, and 105239, and by Staatssekretariat für Bildung und Forschungcontract COST D35 C06.0016. Great thanks to all our co-workers who have contributed to this work: W. Gawelda, C. Consani, M. Prémont-Schwarz, V.-T. Pham, A. ElNahhas, R. M. van der Veen and M. Kaiser. We also acknowledge the great collaboration with the team at the MicroXAS beamline at the Swiss Light Source (PSI, Villigen): S. Johnson, P. Beaud, D. Grolimund, C. N. Borca, G. Ingold, R. Abela. Many thanks to M. Benfatto (Rome) for his theoretical support and A. Hauser (Geneva) and A. Vlček (London) for many fruitful discussions. 


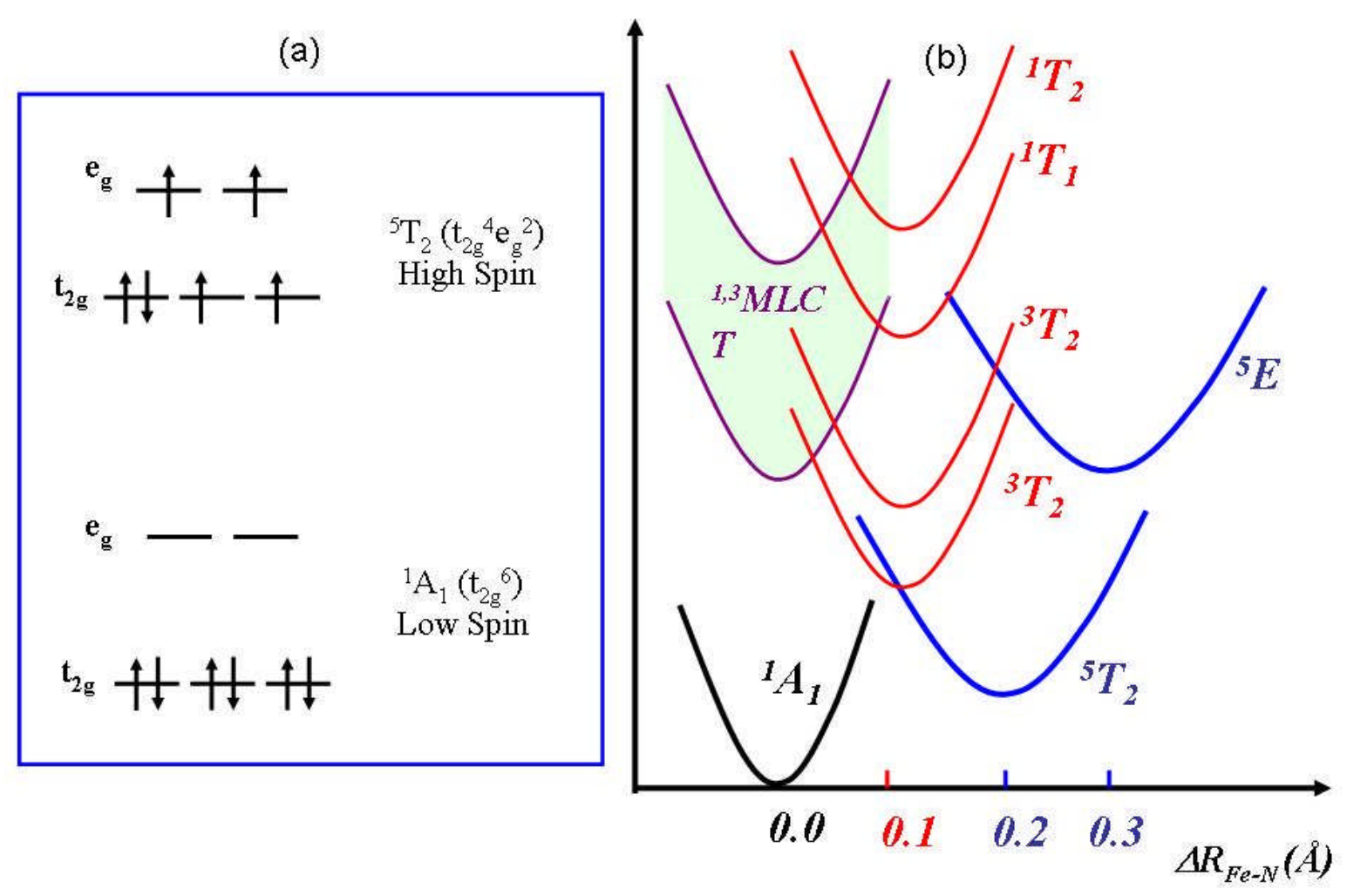

Figure 1

a) Occupancy of the ligand-field split d-orbitals in the low and high spin states; b) typical energy level scheme of $\mathrm{Fe}$ (II)-based molecular complexes displaying both the low-spin (LS) ground state ${ }^{1} \mathrm{~A}_{1}$ and the lowest-lying excited high-spin (HS) state ${ }^{5} \mathrm{~T}_{2}$, together with the intermediate metal-to-ligand charge transfer (MLCT) and the ${ }^{1,3} \mathrm{~T}$ ligand-field (LF) states. This scheme is inspired from refs [16-18, 20, 24]. 

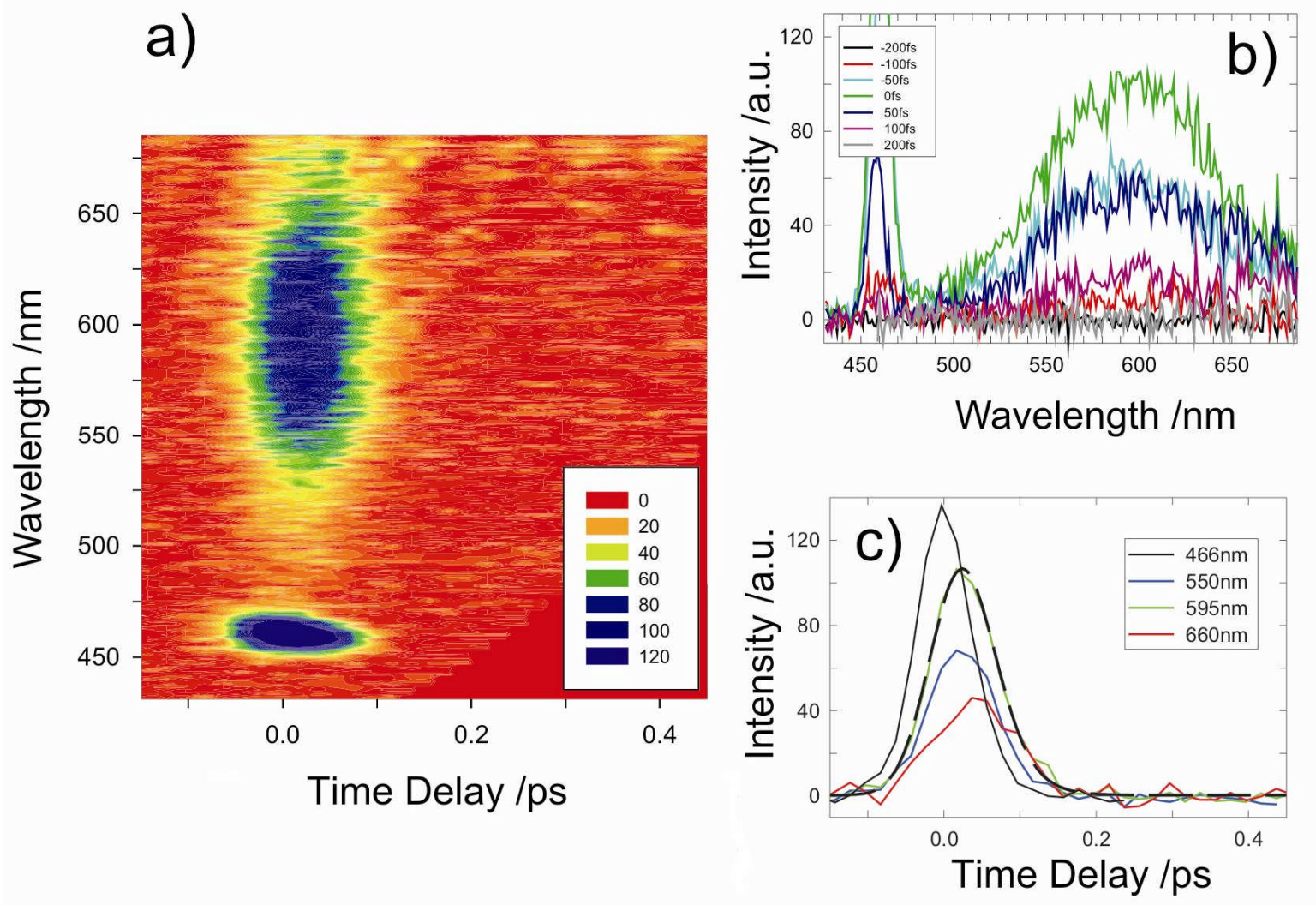

Figure 2

a) Two-dimensional plot of the femtosecond fluorescence spectra of aqueous $\left[\mathrm{Fe}^{\mathrm{II}}(\mathrm{bpy})_{3}\right]^{2+}$ upon excitation at $400 \mathrm{~nm}$. The signal at $466 \mathrm{~nm}$ corresponds to a Raman line of $\mathrm{H}_{2} \mathrm{O}$.

b) Fluorescence spectra at different time delays.

c) Time traces at different wavelengths. Time delays are taken with respect to the water Raman line. The trace at $595 \mathrm{~nm}$ is shown together with its fit function. See ref. [47] for details. 


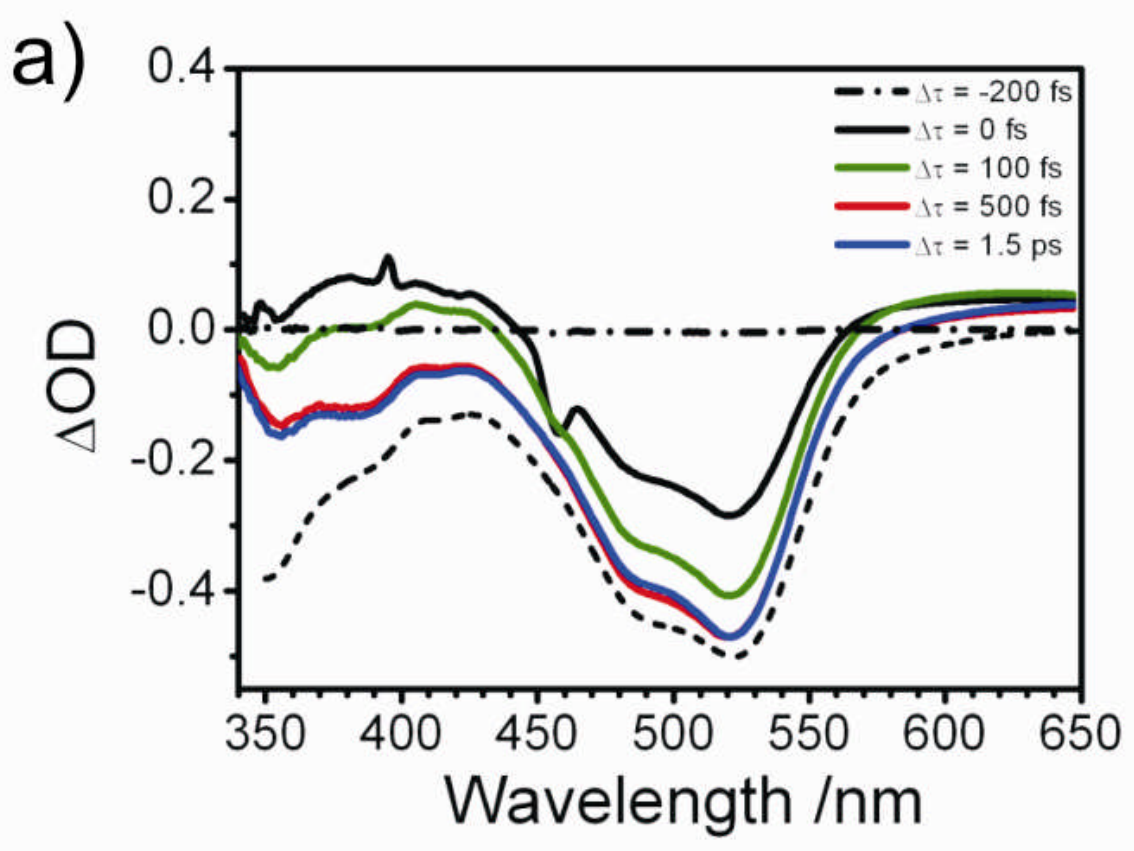

b)

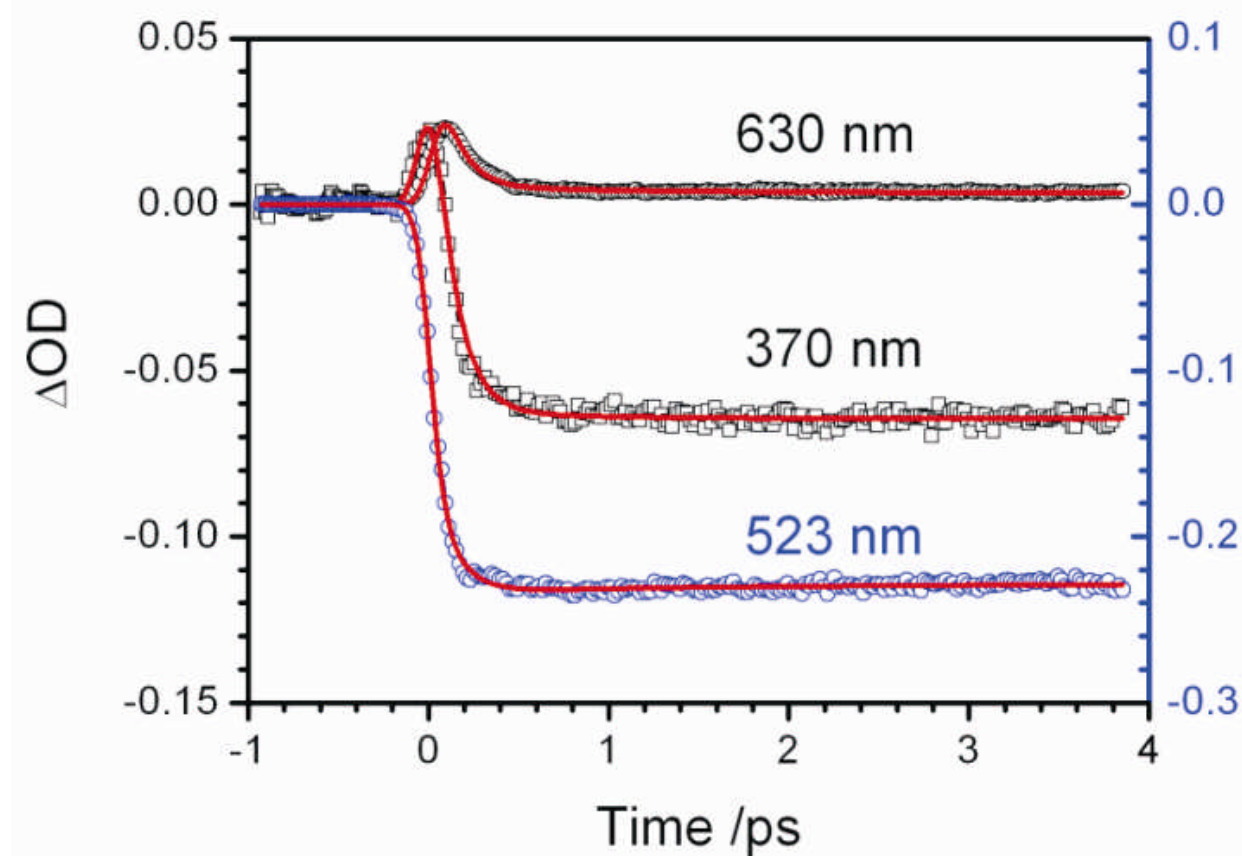

\section{Figure 3}

a) Transient absorption spectra of aqueous $\left[\mathrm{Fe}^{\mathrm{II}}(\mathrm{bpy})_{3}\right]^{2+}$ upon $400 \mathrm{~nm}$ excitation. The spectral evolution in the first 1.5 ps after photoexcitation $(\mathrm{t}=0)$ is shown. The peak around $400 \mathrm{~nm}$ at $\mathrm{t}=0$ is the residual scattered light contribution from the pump pulse. The strong negative absorption feature present in the early spectra around 450$460 \mathrm{~nm}$ is the impulsively-induced Raman signal of $\mathrm{H}_{2} \mathrm{O}$. The inverted ground state absorption spectrum is displayed (dashed line) for comparison.

b) Kinetic traces of aqueous $\left[\mathrm{Fe}^{\mathrm{II}}(\mathrm{bpy})_{3}\right]^{2+}$ in a 5 ps time window at 3 selected wavelengths, together with their fit functions using a global fit model (see ref. [47] for details). 

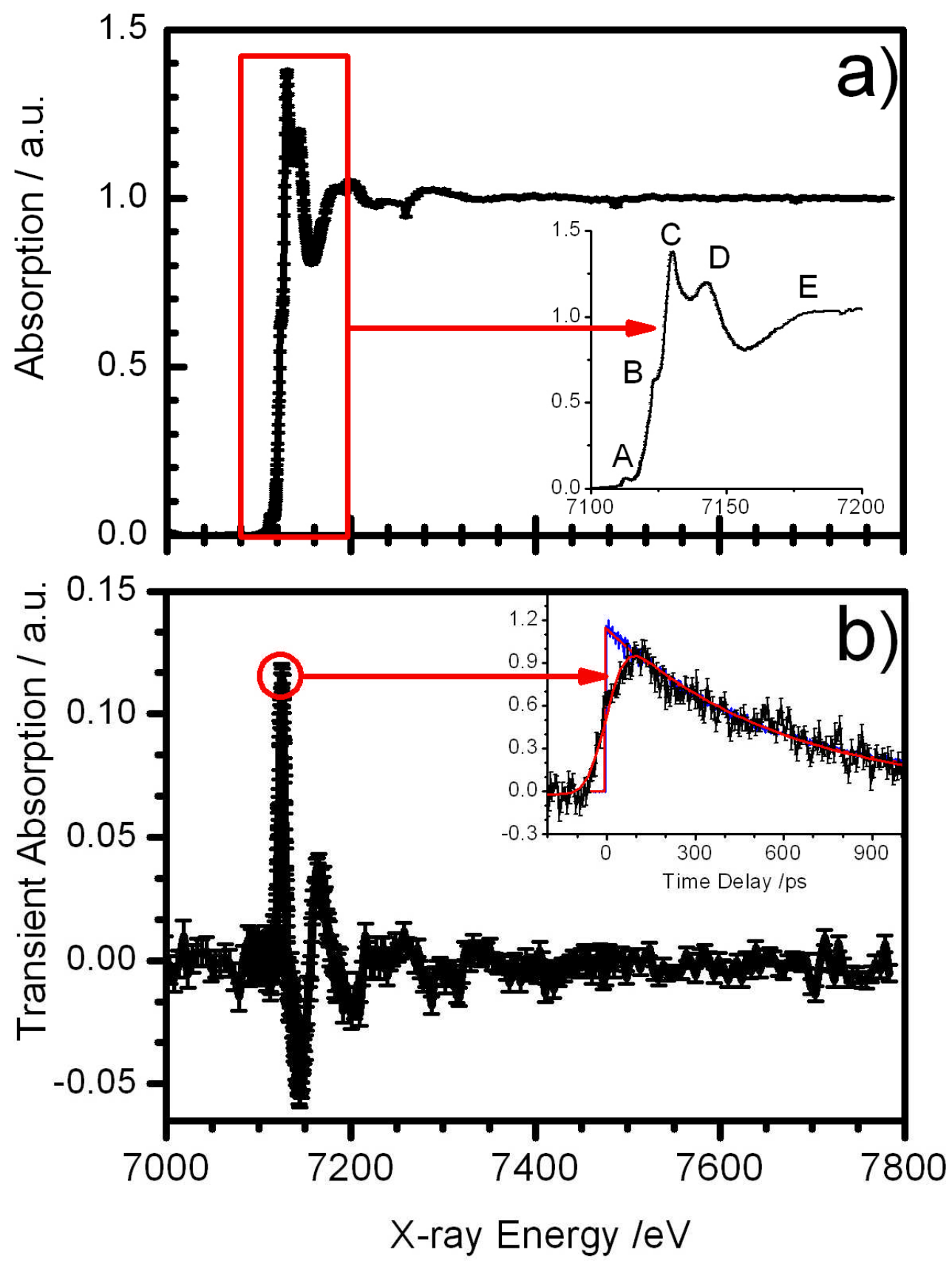

\section{Figure 4}

a) $K$-edge x-ray absorption spectrum of the ground LS state of aqueous $\left[\mathrm{Fe}^{\mathrm{II}}(\mathrm{bpy})_{3}\right]^{2+}$. The inset zooms into the first $100 \mathrm{eV}$ of the spectrum and displays the details of the absorption edge and the nearest-lying XANES resonances (labeled from A-D). The onset of the EXAFS range is represented by the E feature.

b) Transient difference spectrum, recorded $50 \mathrm{ps}$ after the laser pump pulse, with its error bars. The inset displays the kinetics traces of the transient $\mathrm{x}$-ray absorption signal recorded at $7126 \mathrm{eV}$ (feature $\mathrm{B}$ ) as compared to the optical signal (blue) recorded in transmission at $523 \mathrm{~nm}$. The rise time of the x-ray signal is determined by the 70 ps width of the x-ray probe pulse. 
(a)

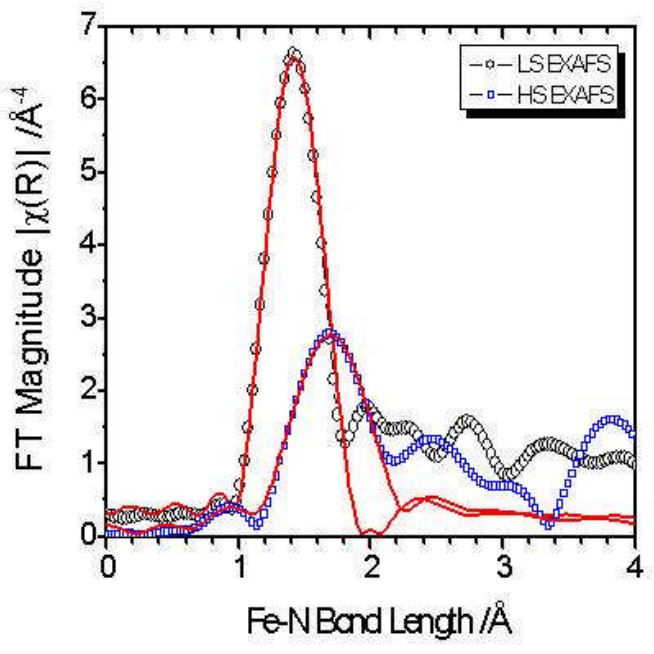

(b)
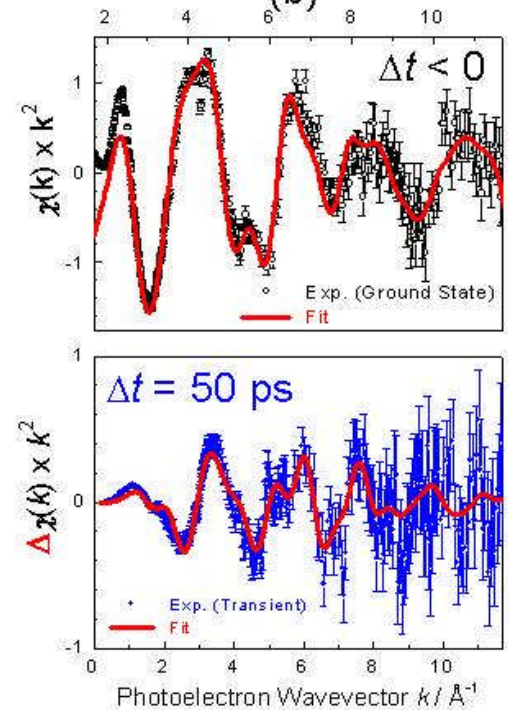

\section{Figure 5}

a) The Fourier power spectra of $\mathrm{k}^{3}$-weighted EXAFS spectra of the LS (circles) and HS (squares) complexes together with their fits (solid lines) using a first-shell model with 6 nearest neighbour $\mathrm{N}$ atoms. See ref. [58] for details.

b) Top: fit of the EXAFS spectrum of the ground state structure. Bottom: Fit of the difference EXAFS spectrum in energy space. See ref. [59] for details. Both approaches deliver an Fe-N bond elongation of $\sim 0.2 \AA$ in the HS state, but the latter fit delivers a much smaller uncertainty ( $\pm 0.008 \AA$ ) 


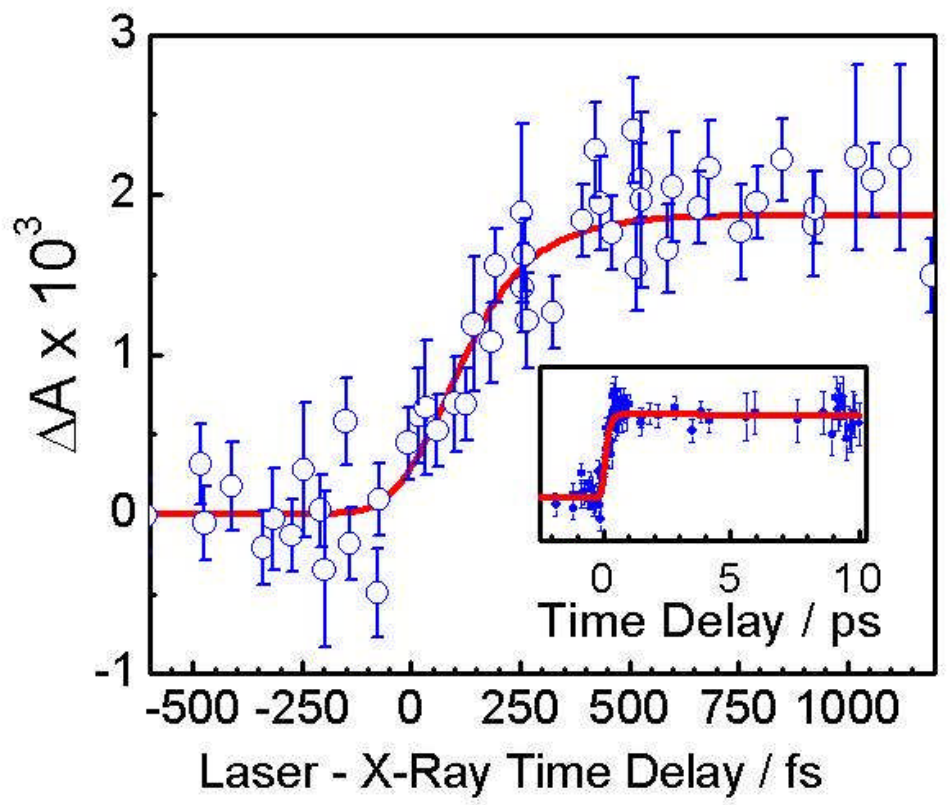

\section{Figure 6}

Femtosecond XANES results: time scan of the signal (blue points) at the B-feature (Fig. 6), as a function of laser pump/x-ray probe time delay after excitation of aqueous $\left[\mathrm{Fe}^{\mathrm{II}}(\mathrm{bpy})_{3}\right]^{2+}$ at $400 \mathrm{~nm}$. The inset shows a long time scan up to $10 \mathrm{ps}$ time delay. The red trace is the simulated signal assuming a simple 4-step kinetic model ${ }^{1} \mathrm{~A}_{1} \rightarrow{ }^{1} \mathrm{MLCT} \rightarrow{ }^{3} \mathrm{MLCT} \rightarrow{ }^{5} \mathrm{~T}$ to describe the spin conversion process. See ref. [42] for details. 


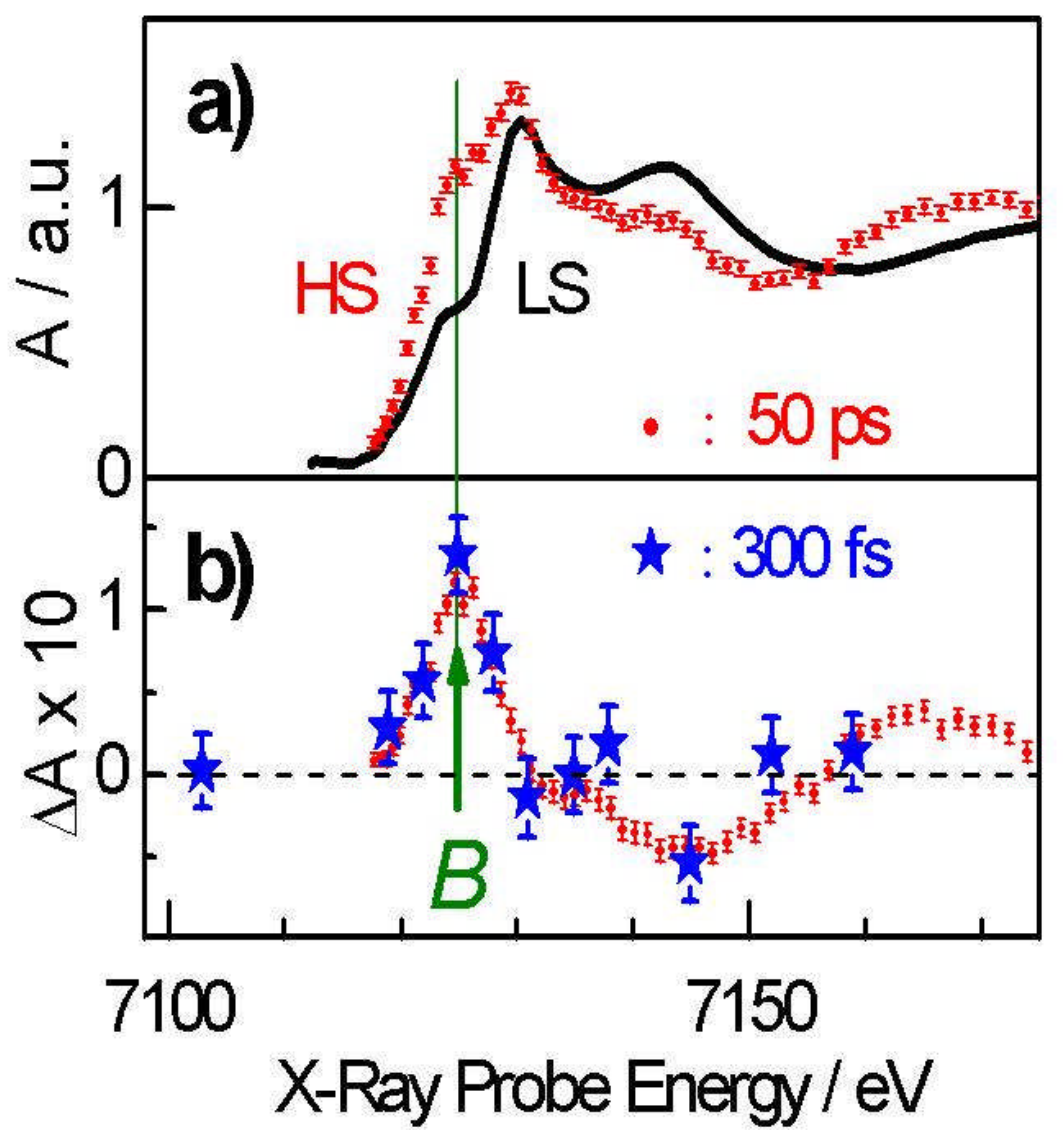

Figure 7

a) XANES spectrum of the LS state of $\left[\mathrm{Fe}^{\mathrm{II}}(\mathrm{bpy})_{3}\right]^{2+}$ (circles) and of the HS state extracted from the transient spectrum at 50 ps time delay shown in (b). (b) Transient XANES spectrum at 50 ps (red dots) and at 300 fs (blue stars) time delays. See ref. [42] for details. 


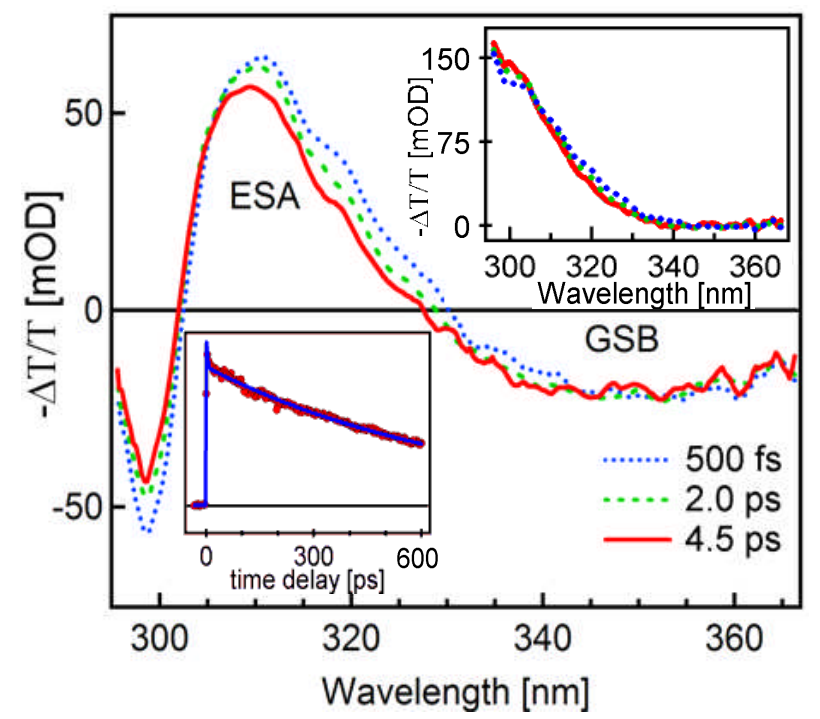

\section{Figure 8}

UV transient absorption spectra at different time delays upon excitation of aqueous $\left[\mathrm{Fe}^{\mathrm{II}}(\mathrm{bpy})_{3}\right]^{2+}$ at $530 \mathrm{~nm}$. The lower inset shows a long-time kinetic trace recorded at $315 \mathrm{~nm}$. The upper inset shows the excited state absorption spectra at different time delays, obtained by subtracting the ground state spectrum from the transient spectra. See ref. [64] for details 


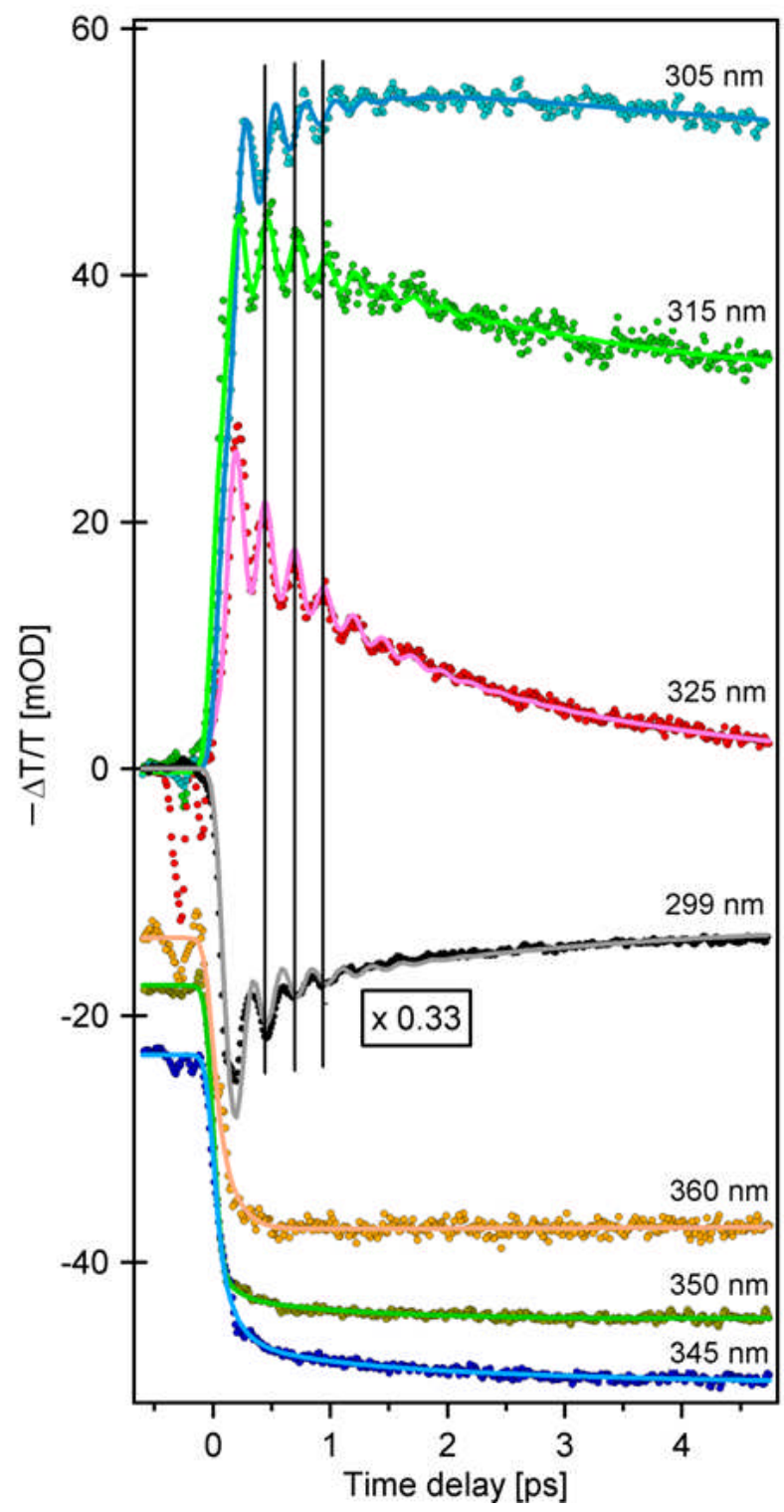

Figure 9

Kinetic traces at different probe wavelengths covering the ESA $(305,315$ and $325 \mathrm{~nm})$ and the bleach regions $(299,345,350$ and $360 \mathrm{~nm})$ in figure 9. Solid lines represent the fits with a bimodal relaxation kinetics and an oscillatory contribution (see text and ref. [64] for details). The vertical lines show the phase shift of $\sim \pi$ of the oscillations between the blue most and the red most probe wavelengths in the ESA region. For sake of clarity time-traces at $\lambda>340 \mathrm{~nm}$ have been vertically shifted and the $299 \mathrm{~nm}$ one is scaled to $1 / 3$. 


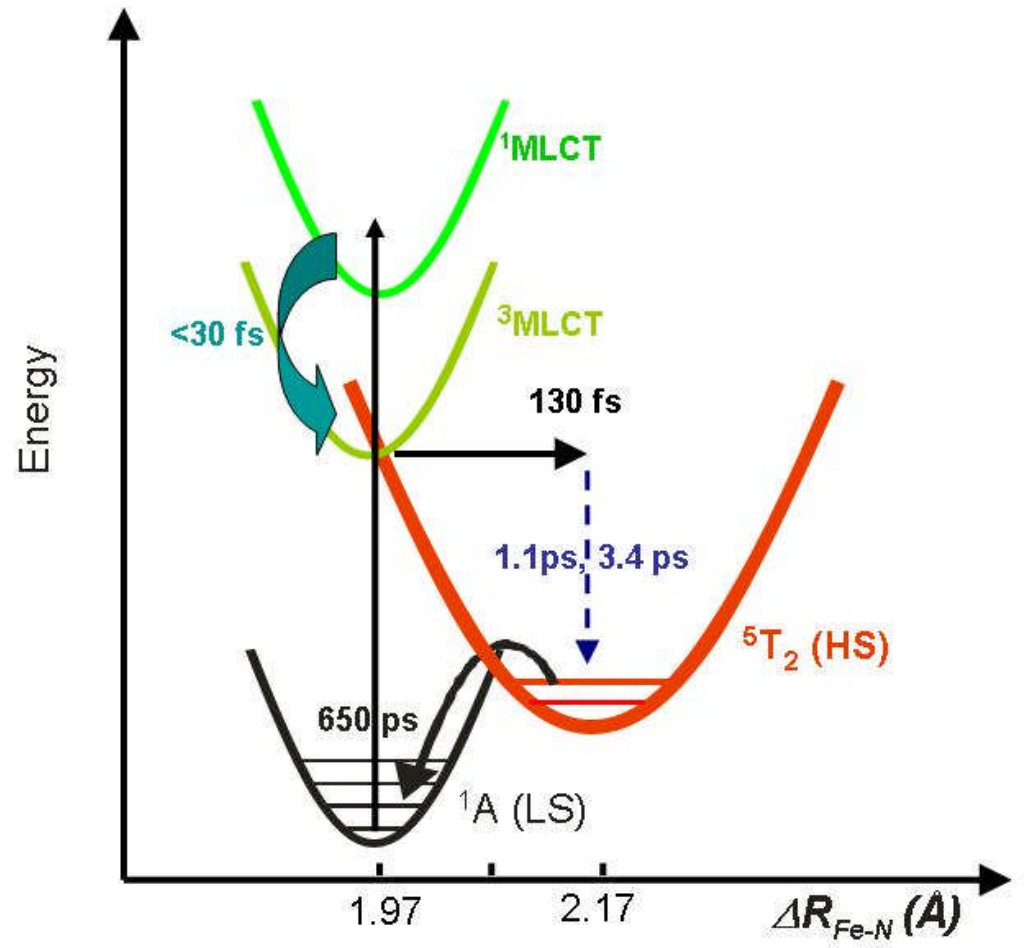

Figure 10

The full photocycle of the ultrafast light-induced spin cross over process in $\left[\mathrm{Fe}^{\mathrm{II}}(\mathrm{bpy})_{3}\right]^{2+}$ in water at room temperature. 


\section{REFERENCES}

[1] P. Gütlich, H.A. Goodwin, Top. Curr. Chem., 233 (2004) 1-47.

[2] J.J. McGarvey, I. Lawthers, K. Heremans, H. Toftlund, J. Chem. Soc.-Chem. Commun., (1984) $1575-1576$.

[3] I. Lawthers, J.J. Mcgarvey, J. Am. Chem. Soc., 106 (1984) 4280-4282.

[4] S. Decurtins, P. Gütlich, K.M. Hasselbach, A. Hauser, H. Spiering, Inorg. Chem., 24 (1985) 2174-2178.

[5] A. Hauser, Chem. Phys. Lett., 124 (1986) 543-548.

[6] A. Hauser, Chem. Phys. Lett., 173 (1990) 507-512.

[7] A. Hauser, Coord. Chem. Rev., 111 (1991) 275-290.

[8] A. Hauser, J. Chem. Phys., 94 (1991) 2741-2748.

[9] A. Hauser, Chem. Phys. Lett., 192 (1992) 65-70.

[10] A. Hauser, Comments Inorganic Chem., 17 (1995) 17-40.

[11] A. Hauser, Spin Crossover in Transition Metal Compounds I, 233 (2004) 49-58.

[12] A. Hauser, Top. Curr. Chem., 234 (2004) 155-198.

[13] A. Hauser, P. Adler, S. Deisenroth, P. Gütlich, C. Hennen, H. Spiering, A. Vef, Hyperfine Interact., 90 (1994) 77-87.

[14] J.F. Letard, P. Guionneau, L. Goux-Capes, Spin Crossover in Transition Metal Compounds III, 235 (2004) 221-249.

[15] J.E. Monat, J.K. McCusker, J. Am. Chem. Soc., 122 (2000) 4092-4097.

[16] L.M.L. Daku, A. Vargas, A. Hauser, Private communication, (2008).

[17] J.H. Rodriguez, J. Chem. Phys., 123 (2005) -.

[18] B. Ordejon, C. de Graaf, C. Sousa, J. Am. Chem. Soc., 130 (2008) 13961-13968.

[19] B.N. Figgis, M.A. Hitchman, Ligand field theory and its applications, Wiley-VCH, New York, 2000. 
[20] N. Suaud, M.L. Bonnet, C. Boilleau, P. Labeguerie, N. Guihery, J. Am. Chem. Soc., 131 (2009) 715-722.

[21] P. Guionneau, M. Marchivie, G. Bravic, J.F. Letard, D. Chasseau, Top. Curr. Chem., 234 (2004) 97-128.

[22] K. Okamoto, K. Nagai, J. Miyawaki, H. Kondoh, T. Ohta, Chem. Phys. Lett., 371 (2003) 707-712.

[23] H. Oyanagi, T. Tayagaki, K. Tanaka, J. Phys. Chem. Solids, 65 (2004) 1485-1489.

[24] L.M.L. Daku, A. Vargas, A. Hauser, A. Fouqueau, M.E. Casida, Chemphyschem, 6 (2005) 1393-1410.

[25] J.P. Tuchagues, A. Bousseksou, G. Molnar, J.J. McGarvey, F. Varret, Top. Curr. Chem., 235 (2004) 85-103.

[26] J.K. McCusker, H. Toftlund, A.L. Rheingold, D.N. Hendrickson, J. Am. Chem. Soc., 115 (1993) 1797-1804.

[27] J.K. McCusker, K.N. Walda, R.C. Dunn, J.D. Simon, D. Magde, D.N. Hendrickson, J. Am. Chem. Soc., 114 (1992) 6919-6920.

[28] J.K. McCusker, K.N. Walda, R.C. Dunn, J.D. Simon, D. Magde, D.N. Hendrickson, J. Am. Chem. Soc., 115 (1993) 298-307.

[29] J.K. McCusker, A.L. Rheingold, D.N. Hendrickson, Inorg. Chem., 35 (1996) 2100-2112. [30] J.K. McCusker, Accounts Chem. Res., 36 (2003) 876-887.

[31] C. Brady, J.J. McGarvey, J.K. McCusker, H. Toftlund, D.N. Hendrickson, Top. Curr. Chem., 235 (2004) 1-22.

[32] E.A. Juban, A.L. Smeigh, J.E. Monat, J.K. McCusker, Coord. Chem. Rev., 250 (2006) 1783-1791.

[33] C. Brady, P.L. Callaghan, Z. Ciunik, C.G. Coates, A. Dossing, A. Hazell, J.J. McGarvey, S. Schenker, H. Toftlund, A.X. Trautwein, H. Winkler, J.A. Wolny, Inorg. Chem., 43 (2004) 4289-4299. 
[34] A.L. Smeigh, M. Creelman, R.A. Mathies, J.K. McCusker, J. Am. Chem. Soc., 130 (2008) 14105-+.

[35] M. Vengris, M.A. van der Horst, G. Zgrablic, I.H.M. van Stokkum, S. Haacke, M. Chergui, K.J. Hellingwerf, R. van Grondelle, D.S. Larsen, Biophys. J., 87 (2004) 1848-1857. [36] G. Zgrablic, K. Voitchovsky, M. Kindermann, S. Haacke, M. Chergui, Biophys. J., 88 (2005) 2779-2788.

[37] A. Cannizzo, F. van Mourik, W. Gawelda, G. Zgrablic, C. Bressler, M. Chergui, Angew. Chem. -Int. Edit., 45 (2006) 3174-3176.

[38] A. Cannizzo, O. Bram, G. Zgrablic, A. Tortschanoff, A.A. Oskouei, F. van Mourik, M. Cherguil, Opt. Lett., 32 (2007) 3555-3557.

[39] J. Helbing, L. Bonacina, R. Pietri, J. Bredenbeck, P. Hamm, F. van Mourik, F. Chaussard, A. Gonzalez-Gonzalez, M. Chergui, C. Ramos-Alvarez, C. Ruiz, J. LopezGarriga, Biophys. J., 87 (2004) 1881-1891.

[40] C. Bressler, M. Chergui, Chem. Rev., 104 (2004) 1781-1812.

[41] C. Bressler, R. Abela, M. Chergui, Z. Kristall., 223 (2008) 307-321.

[42] C. Bressler, C. Milne, V.T. Pham, A. ElNahhas, R.M. van der Veen, W. Gawelda, S. Johnson, P. Beaud, D. Grolimund, M. Kaiser, C.N. Borca, G. Ingold, R. Abela, M. Chergui, Science, 323 (2009) 489-492.

[43] M. Saes, C. Bressler, F. van Mourik, W. Gawelda, M. Kaiser, M. Chergui, C. Bressler, D. Grolimund, R. Abela, T.E. Glover, P.A. Heimann, R.W. Schoenlein, S.L. Johnson, A.M. Lindenberg, R.W. Falcone, Rev. Sci. Instrum., 75 (2004) 24-30.

[44] W. Gawelda, C. Bressler, M. Saes, M. Kaiser, A. Tarnovsky, D. Grolimund, S.L. Johnson, R. Abela, M. Chergui, Phys. Scr., T115 (2005) 102.

[45] R.W. Schoenlein, S. Chattopadhyay, H.H.W. Chong, T.E. Glover, P.A. Heimann, C.V. Shank, A.A. Zholents, M.S. Zolotorev, Science, 287 (2000) 2237-2240. 
[46] P. Beaud, S.L. Johnson, A. Streun, R. Abela, D. Abramsohn, D. Grolimund, F. Krasniqi, T. Schmidt, V. Schlott, G. Ingold, Phys. Rev. Lett., 99 (2007) 174801.

[47] W. Gawelda, A. Cannizzo, V.T. Pham, F. van Mourik, C. Bressler, M. Chergui, J. Am. Chem. Soc., 129 (2007) 8199-8206.

[48] P.S. Braterman, J.I. Song, R.D. Peacock, Inorg. Chem., 31 (1992) 555-559.

[49] A. Tarnovsky, W. Gawelda, M. Johnson, C. Bressler, M. Chergui, J. Phys. Chem. B, 110 (2006) 26497-26505.

[50] W. Gawelda, Thesis EPFL, (2006).

[51] M. Khalil, M.A. Marcus, A.L. Smeigh, J.K. McCusker, H.H.W. Chong, R.W. Schoenlein, J. Phys. Chem. A, 110 (2006) 38-44.

[52] V. Briois, C.C.D. Moulin, P. Sainctavit, C. Brouder, A.M. Flank, J. Am. Chem. Soc., 117 (1995) 1019-1026.

[53] V. Briois, P. Sainctavit, G.J. Long, F. Grandjean, Inorg. Chem., 40 (2001) 912-918.

[54] M.L. Boillot, J. Zarembowitch, J.P. Itie, A. Polian, E. Bourdet, J.G. Haasnoot, New J. Chem., 26 (2002) 313-322.

[55] H. Oyanagi, T. Tayagaki, K. Tanaka, J. Lumin., 119 (2006) 361-369.

[56] T. Yokoyama, Y. Murakami, M. Kiguchi, T. Komatsu, N. Kojima, Phys. Rev. B, 58 (1998) 14238-14244.

[57] R. Boca, M. Vrbova, R. Werner, W. Haase, Chem. Phys. Lett., 328 (2000) 188-196.

[58] W. Gawelda, V.T. Pham, M. Benfatto, Y. Zaushitsyn, M. Kaiser, D. Grolimund, S.L. Johnson, R. Abela, A. Hauser, C. Bressler, M. Chergui, Phys. Rev. Lett., 98 (2007) 057401. [59] W. Gawelda, V.T. Pham, R.M. Van der Veen, D. Grolimund, R. Abela, M. Chergui, C. Bressler, J. Chem. Phys., 130 (2009) 124520.

[60] C. Enachescu, U. Oetliker, A. Hauser, J. Optoelectron. Adv. Mater., 5 (2003) 267-272.

[61] C. Creutz, M. Chou, T.L. Netzel, M. Okumura, N. Sutin, J. Am. Chem. Soc., 102 (1980) 1309-1319. 
[62] M.A. Bergkamp, C.K. Chang, T.L. Netzel, Journal of Physical Chemistry, 87 (1983) 4441-4446.

[63] M.M.N. Wolf, R. Gross, C. Schumann, J.A. Wolny, V. Schunemann, A. Dossing, H. Paulsen, J.J. McGarvey, R. Diller, Phys. Chem. Chem. Phys., 10 (2008) 4264-4273.

[64] C. Consani, M. Prémont-Schwarz, A. Elnahhas, C. Bressler, F. van Mourik, A. Cannizzo, M. Chergui, Angew. Chem. -Int. Edit., 48 (2009) 7184 -7187.

[65] B.D. Alexander, T.J. Dines, R.W. Longhurst, Chem. Phys., 352 (2008) 19-27.

[66] F. Rosca, A.T.N. Kumar, D. Ionascu, X. Ye, A.A. Demidov, T. Sjodin, D. Wharton, D. Barrick, S.G. Sligar, T. Yonetani, P.M. Champion, J. Phys. Chem. A, 106 (2002) 3540-3552.

[67] G. Zgrablic, S. Haacke, M. Chergui, Chem. Phys., 338 (2007) 168-174.

[68] M. Besora, J.L. Carreon-Macedo, A. Cimas, J.N. Harvey, Advances in Inorganic Chemistry, Vol 61: Metal Ion Controlled Reactivity, 61 (2009) 573-623.

[69] P.M. Champion, F. Rosca, D. Ionascu, W.X. Cao, X. Ye, Faraday Discussions, 127 (2004) 123-135.

[70] A. Lapini, P. Foggi, L. Bussotti, R. Righini, A. Dei, Inorg. Chim. Acta, 361 (2008) 39373943. 